\title{
ANALISA HIDROLOGI DAN HIDROLIKA PADA DAERAH ALIRAN SUNGAI (DAS) KALI PACAL BOJONEGORO
}

\author{
Harjono $^{*}$, Yulis Widhiastuti ${ }^{2}$ \\ ${ }^{1}$ Program Studi Teknik Sipil / Universitas Bojonegoro \\ ${ }^{2}$ Program Studi Teknik Sipil / Universitas Bojonegoro \\ Korespondensi: haryono_adhi@yahoo.co.id
}

\begin{abstract}
Erosion and sedimentation are two interrelated problems. In the Pacal river catchment area, in its development there has been environmental damage which has caused problems in watershed management in the form of changes in the function of paddy fields which basically results in a decline in the amount of water demand. The aim of the study was to monitor and evaluate the performance of the Pacal River sub-watershed using water management criteria. The results of the study found that the Flood calculation for 5 years with the Harpes method with Debit yields of 443,678 $\mathrm{m}^{3} / \mathrm{sec}$, the Rational method produced 413,495 $\mathrm{m}^{3} / \mathrm{sec}$ and the Melchoir method produced $412,824 \mathrm{~m}^{3} / \mathrm{sec}$.
\end{abstract}

Keywords : Chekdam, sedimentation, Pacal River

\section{PENDAHULUAN}

Daerah tangkapan air wilayah Kali Pacal, dalam perkembangannya telah terjadi kerusakan lingkungan yang disebabkan adanya berubahnya tata gunalahan dan hal ini menyebabkan tingkat erosi meningkat sehingga berakibat padapeningkatan sedimentasi pada bangunan bangunan air yang sudah ada sepertipada Bendung Klepek. Untuk itu perlu dibuat Check Dam yang dapat mengendalikan sedimen sebelum masuk ke sungai agar bangunan existing dapat diselamatkan kelestariannya yang juga bisa untuk bisa menanmpung sisa air yang bisa dimanfaatkan dengan dibuatkan lubang skot balk diatas mercu bendung serta penyediaan skot balknya, dimaksudkan agar tampungan air sisa dimusim penghujan dapat dimanfaatkan dimusim kemarau dengan sitem pompa oleh para petani.

Pola penyebaran sedimentasi di dasar Bendung tergantung dari topografi bendung,ukuran butir sedimen, dan pola operasi bendung. Pengaruh sedimentasi terhadap berkurangnya volume bendung dapat menyebabkan berkurangnya volume efektif bendung dan tingkat operasional bendung. Dalam makalah ini akan dibahas mengenai desain Bangunan Pengendali Sedimen (Check Dam) dengan tujuan menganalisis debit banjir, menghitung dimensi Check Dam guna mengurangi sedimentasi di sungai bagian hilir yang menyebabkan air meluap, dan menentukan stabilitas Check Dam.

Analisa hidrologi digunakan untuk memprediksi debit air yang masuk pada kala ulang 5 tahun atau 10 tahun. Analisa hidrolika ini juga digunakan untuk menentukan kapasitas saluran dengan memperhatikan sifat-sifat hidrolika yang terjadi pada daerah aliran kali pacal tersebut. Sifat-sifat tersebut meliputi jenis aliran (steady atau unsteady), angka kekasaran (manning) dan sifat alirannya (kritis, subkritis dan superkritis).

Penelitian ini bertujuan untuk mengetahui kala ulang berapa tahun debit maksimum saluran akan terlampaui dan untuk mengetahui kapasitas saluran drainase di wilayah aliran kali pacal berdasarkan analisis hidrologi dan hidrolika menggunakan menggunkan 3 metode perhitungan yaitu metode harpers, metode rasional dan metode melchoir

\section{TINJAUAN PUSTAKA 2.1 Erosi dan Sedimentasi}

Erosi dan sedimentasi merupakan dua buah masalah yang saling berkaitan. Erosi tanah yang meliputi proses pelepasan butir - butir tanah dan proses pemindahan tanah akan menyebabkan 
timbulnya bahan endapan atau sedimentasi ditempat lain. Pada saat permulaan turun hujan, pukulan jatuhnya air hujan merupakan penghasil utama butir - butir yang terlepas dalam erosi tanah. Bersama dengan aliran air, butir - butir tanah yang lepas akibat proses erosi akan diangkut masuk dalam aliran sungai dan kemudian akan diendapkan pada tempat tempat tertentu (pada muara sungai dan waduk) berupa pengendapan atau sedimentasi. Endapan sedimen tersebut apabila semakin lama semakin terakumulasi jumlahnya, maka akan menimbulkan pendangkalan pada waduk dan muara sungai yang selanjutnya akan berakibat terhadap berkurangnya umur rencan waduk. Banyaknya angkutan bahan endapan tergantung dari besarnya erosi tanah yang terjadi. Semakin banyak jumlah bahan sedimen yang terangkut menunjukkan makin besar tingkat erosi tanah yang terjadi dalam daerah aliran sungai yang bersangkutan. Karena erosi dan sedimentasi merupakan suatu hal yang saling memiliki keterkaitan, maka dibawah ini akan dibahas kedua masalah tersebut.

Terdapat dua faktor yang menyebabkan terjadinya proses erosi, yaitu faktor penyebab terjadinya erosi yang dinyatakan dalam erosivitas dan faktor tanah yang dinyatakan dalam erodibilitas.

a. Erosivitas

b. Erodibilitas

Secara umum, faktor - faktor tersebut dapat dinyatakan dengan persamaan yang dikenal sebagai Persamaan Umum Kehilangan Tanah ( PUKT ) yaitu :

$$
\boldsymbol{A} * \boldsymbol{R} * \boldsymbol{K} * \boldsymbol{L} * \boldsymbol{S} * \boldsymbol{C} * \boldsymbol{P}
$$

Proses terjadinya sedimentasi merupakan bagian dari proses erosi tanah.timbulnya bahan sedimen adalah sebagai akibat dari erosi tanah yang terjadi.proses erosi dan sedimentasi di indonesia yang lebih berperan adalah faktor air, sedangkan faktor angin relatif kecil

a. Perhitungan debit sedimen melayang (suspended load) Metode perhitungan berdasarkan pengukuran sesaat Rumus :

$$
\boldsymbol{Q} \mathrm{s}=0,0864 * \boldsymbol{C} * \boldsymbol{Q w}
$$

b. Perhitungan Sedimen dasar (Bed Load)

1. Pengukuran sedimen dasar cara langsung

2. Pengukuran sedimen dasar dengan cara tidak langsung

3. Perkiraan muatan sedimen dasar dengan rumus empiris
Untuk perhitungan volume sedimen dapat di gunakan rumus sebagai berikut :

$\mathbf{P s}=\mathbf{R} \quad \mathbf{s} \mathbf{A} \quad \mathbf{A} / \mathbf{F}$

Volume sedimen total

$V s t=V a m+V a d$

\subsection{Metode Analisis Data Hidrologi}

Metode Perhitungan Curah Hujan

a. Metode Perhitungan Rata-Rata Rumus :

$$
\boldsymbol{R}_{\text {ave }}=\frac{\boldsymbol{R} \mathbf{1}+\boldsymbol{R 2}+\boldsymbol{R} \mathbf{3}+\cdots \ldots \ldots \ldots \ldots \boldsymbol{n} \boldsymbol{n}}{\boldsymbol{n}}
$$

(Cara Menghitung Design Flood)

Metode Isohyet Urutan perhitungannya adalah sebagai berikut :

Luas areal diantara dua buah isohyet di ukur dengan planimeter

$$
=\text { An, } n-1
$$

Curah hujan rata-rata antara dua buah isohyets :

$$
\begin{aligned}
& =\mathrm{Rm}, \mathrm{n}-1, \mathrm{t} \ldots \ldots \ldots \ldots \ldots \ldots \\
& \text { Volume hujan pada isohyet } \mathrm{n} \text { : } \\
& =\mathrm{Rn}, \mathrm{n}-1, \mathrm{t} * \text { An, } \mathrm{n}-1 \ldots \ldots \ldots
\end{aligned}
$$

b. Metode Poligon Thiessen

$$
\begin{aligned}
\mathrm{R}= & (\mathrm{A} 1 \mathrm{R} 1+\mathrm{A} 2 \mathrm{R} 2+\mathrm{A} 3 \mathrm{R} 3+\cdots \ldots \ldots \ldots \ldots \\
& +\mathrm{AnRn}) /(\mathrm{A} 1+\mathrm{A} 2+\mathrm{A} 3+\cdots \ldots \ldots+\mathrm{An})
\end{aligned}
$$

c. Metode Analisis Frekuensi

Cara mengukur besarnya disperse antara lain :

Harga rata-rata $(\mathrm{X})$

Rumus :

$$
\mathrm{X}^{\wedge} \_=\sum \mathrm{i}^{\wedge} \mathrm{nx} \_1
$$

Standart deviasi (Sx)

Rumus :

$$
\mathrm{Sx}=\sqrt{ }\left(\sum(\mathrm{i}=1)^{\wedge} \mathrm{n}\left[\mathrm{Xi}-\mathrm{X}^{\wedge}-\right]\right)
$$

Distribusi Normal

$$
P(X)=\frac{1}{\sqrt{2 \pi}} e \frac{-1}{2}\left(\frac{x-\mu}{\sigma}\right) .
$$

Distribusi Gumbel

$R_{T}=R^{-}+(K * S x)$

Distribusi Log Pearson Type III

Langkah-langkah perhubungannya adalah sebagai berikut :

- Gantilah Data X1,X2,X3 .......Xn menjadi data dalam logaritma yaitu $\log X 2, \log$ X3.........., Log Xn. 
- Hitung rata-rata dari logaritma data tersebut.

$$
\log X^{-}=\frac{\sum_{i}^{n} \log X_{1}}{n}
$$

- Hitung standar deviasi dari logaritma data.

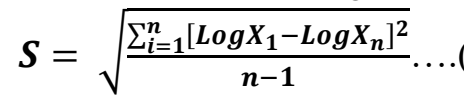

- $\quad$ Hitung Koefisien Skewness

$$
\boldsymbol{C v}=\sqrt{\frac{\sum_{i=1}^{n}\left[\log X_{1}-\log X_{n}\right]^{2}}{(n-1) *(n-2) * S^{3}}}
$$

Hitung logaritma data pada interval pengulangan atau kemungkinan prosentase yang dipilih.

\section{METODE PENELITIAN}

Tipe penelitian yang digunakan adalah tipe penelitian Observasi dan Pengumpulan data yaitu peneliti datang langsung ke wilayah studi untuk mengamati dan meneliti kondisi yang ada, serta mencari dan mengumpulkan data yang diperlukan.

Dengan menggunakan data yang ada sesuai dengan yang sudah di teliti dan sesuai dengan pengumpulan data maka bisa dilakukan pengolahan data untuk kemudian di jadikan suatu pedoman pada proses pembangunan dan pengembangan daerah sesuai dengan tujuannya berdasarkan analisasecara teoritis dan empiris yang kemudian ditarik kesimpulan dari hasil analisa yang telah dilakukan.

\subsection{Teknik Pengumpulan Data}

Dalam memperoleh data untuk penelitian ini dilakukan dengan mengumpulkan data - data yang diperoleh dari data primer dan data sekunder.

1. Data primer

2. Data sekunder adalah data yang diperoleh dari dokumen - dokumen yang dapat dijadikan acuan dalam penelitian ini.

\subsection{Analisis data}

Dalam penelitian ini, analisa data dilakukan berdasarkan analisa data hidrologi

\section{HASIL DAN PEMBAHASAN}

\subsection{Analisa Curah Hujan Rata-Rata}

Perencanaan dam pengendali sedimen kali pacal ini menggunakan data curah hujan dari stasiun yang berpengaruh pada daerah tersebut, yaitu :
1. Stasiun Hujan Klepek

2. Stasiun Hujan Balen

3. Stasiun Hujan Kapas

Adapun rekapitulasi data curah hujan rata-rata dapat dilihat pada Tabel 1.

Tabel 1. Data Curah Hujan Harian Maksimum

\begin{tabular}{|c|c|c|c|c|}
\hline \multirow{2}{*}{ No } & \multirow{2}{*}{ Tahun } & \multicolumn{3}{|c|}{ Nama Stasiun } \\
\cline { 3 - 5 } & & Klepek & Balen & Kapas \\
\hline 1 & 2012 & 490 & 471 & 411 \\
\hline 2 & 2013 & 487 & 469 & 406 \\
\hline 3 & 2014 & 493 & 565 & 462 \\
\hline 4 & 2015 & 399 & 465 & 413 \\
\hline 5 & 2016 & 446 & 358 & 401 \\
\hline
\end{tabular}

( Sumber : Data dinas Pengairan Bojonegoro )

Perhitungan curah hujan harian maksimum rata-rata dimulai dengan mengurutkan data curah hujan dari yang terbesar ke yang terkecil pada tiap-tiap stasiun. Perhitungan curah hujan Rata-rata daerah aliran selanjutnya akan di sajikan dalam Tabel 2.

Tabel 2. Perhitungan Curah Hujan Harian Maksimum Rata-Rata

Sumber : Olah data

\begin{tabular}{|c|c|c|c|c|}
\hline \multirow{2}{*}{$\begin{array}{c}\mathrm{N} \\
\mathrm{o}\end{array}$} & \multicolumn{3}{|c|}{ Nama Stasiun } & \multirow{2}{*}{ Curah Hujan } \\
\cline { 2 - 4 } & $\begin{array}{c}\text { Klepe } \\
\mathrm{n}\end{array}$ & $\begin{array}{c}\text { Kapa } \\
\mathrm{s}\end{array}$ & Rata-Rata \\
\hline 1 & 493 & 565 & 462 & 506,667 \\
\hline 2 & 490 & 471 & 413 & 458,000 \\
\hline 3 & 487 & 469 & 411 & 455,667 \\
\hline 4 & 446 & 465 & 406 & 439,000 \\
\hline 5 & 399 & 358 & 401 & 386,000 \\
\hline
\end{tabular}

\subsection{Analisa Frekuensi}

Ada beberapa jenis distribusi statistik yang dapat dipakai untuk menentukan besarnya curah hujan rencana, seperti distribusi Gumbel, Log Pearson III, Log Normal, dan beberapa cara lain. Metode-metode ini harus diuji mana yang biasa dipakai dalam perhitungan. Pengujian tersebut melalui pengukuran dispersi. Untuk melakukan pengukuran disperse

Untuk menghitung faktor-faktor tersebut di perlukan Parameter - Parameter Perhitungan faktor-faktor tersebut, yang disajikan dalam Tabel 3. 
Tabel 3. Parameter Uji Distribusi Statistik

\begin{tabular}{|c|c|c|c|c|c|}
\hline $\mathrm{N}_{0}$ & $R(X)$ & $(\mathrm{H} . \mathrm{II})$ & $(\mathrm{B} \cdot \mathrm{W}) \mathrm{z}$ & $(\mathrm{X}=\mathrm{I}) / 3$ & $(\mathrm{x}-\mathrm{x} \mathrm{y}) 4$ \\
\hline 1 & 506667 & 57,600 & $3.317,760$ & 191102976 & 11007531,418 \\
\hline 2 & 458000 & 8953 & 79,804 & 712920 & 6368,749 \\
\hline 3 & 455,667 & 6,600 & 43,560 & 87,494 & $1.897,474$ \\
\hline 4 & 439,000 & $-10,067$ & 101,338 & $-1020,134$ & $10.269,345$ \\
\hline 5 & 386,000 & 835,067 & 697336338 & -586322331.134 & 43627796795533 \\
\hline Jumlah & 2245333 & & $700.878,800$ & -582131247876 & 436283994.05238 \\
\hline $\mathrm{XI}$ & 49,067 & & & & \\
\hline
\end{tabular}

Sumber : Olah data

Dari Tabel 3 dapat dihitung faktor - faktor uji distribusi sebagai berikut :

1. Harga rata - rata $\left(X^{-}\right)$

$$
X^{-}=X r=\frac{2245,333}{5}=449,067
$$

2. Standart Deviasi ( $\mathrm{Sx}$ )

$$
S x=\sqrt{\frac{700.878,800}{5-1}=418,593}
$$

3. Koefisien Skewness ( Cs )

$$
\begin{gathered}
C s=\frac{5 x-582.131 .247,876}{(5-1) *(5-2) * 418,593^{3}} \\
=-3,307
\end{gathered}
$$

4. Koefisien Curtosis ( $\mathrm{Ck}$ )

$\mathrm{Ck}$

$$
\begin{aligned}
& =\frac{5 \times 486.288 .994 .052,309}{(5-1) *(5-2) *(5-3) * 418,593^{3}} \\
& =1381,271
\end{aligned}
$$

\begin{tabular}{|c|c|c|c|c|c|c|}
\hline$N_{0}$ & $R\left(X_{i}\right)$ & Lagli & $(\log x=\log x$ & 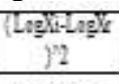 & $\left(\log X_{1}-\log X_{x}\right) 9$ & $(\log \pi-\log x) 4$ \\
\hline 1 & 506,667 & 57,600 & 0,05476495 & 0,00292302 & 0,00015803290 & 0,0000665404 \\
\hline 2 & 458,000 & 8,933 & 0,01020810 & 0,00110421 & 0,00000106372 & 0,00000001086 \\
\hline 3 & 455,667 & 6,600 & 0,00798988 & 0,00006384 & 0,00000051086 & 0,00000000403 \\
\hline 4 & 499,000 & $-10,067$ & $-0,00819286$ & 0,00006712 & 0,00000054993 & 0,00000000451 \\
\hline 5 & 386,000 & $-835,067$ & $-0,06477007$ & 0,00410497 & $-0,000263006602$ & $-0,00001685882$ \\
\hline Jumlah & & 13251 & & 0,00726316 & 9394925 & $-0,1$ \\
\hline $\mathrm{X}_{\mathrm{I}}$ & 49,667 & 2651 & & & & \\
\hline
\end{tabular}

5. Koefisien Variasi

$$
C v=\frac{418,593}{449,067}=0.392
$$

Tabel 4. Parameter Uji Distribusi Statistik dalam Log

Sumber : Olah data
Dari Tabel 4 dapat dihitung faktor - faktor uji distribusi sebagai berikut :

1. Harga rata -rata $\left(X^{-}\right)$

$$
\log X^{-}=X r=\frac{13,253}{5}=2.651
$$

2. Standart Deviasi ( $\mathrm{Sx}$ )

$$
S x=\sqrt{\frac{0.00726316}{5-1}=0.043}
$$

3. Koefisien Skewness ( Cs )

$$
C s=\frac{5 x-0.00010394925}{(5-1) *(5-2) * 0.043^{3}}=-0,560
$$

4. Koefisien Curtosis ( $\mathrm{Ck}$ )

$$
\begin{gathered}
C k=\frac{5 \times 0,00002541430}{(5-1) *(5-2) *(5-3) * 0.043^{3}} \\
=0.068
\end{gathered}
$$

5. Koefisien Variasi

$$
C v=\frac{0.043}{2,651}=0,016
$$

Dari faktor - faktor diatas dapat ditentukan metode mana yang bias dipakai, seperti disajikan dalam Tabel 5.

Tabel 5. Hasil uji distribusi Statiktik

\begin{tabular}{|c|l|l|c|}
\hline $\begin{array}{c}\text { jenis } \\
\text { Distribusi }\end{array}$ & Syarat & Perhitungan & Kesimpulan \\
\hline Normal & $\mathrm{Cs} \approx 0$ & $\begin{array}{l}\mathrm{Cs}=-3,307 \\
\mathrm{Ck}=\end{array}$ & $\begin{array}{c}\text { Tidak } \\
\text { Memenuhi }\end{array}$ \\
\hline & $\mathrm{Ck}=0$ & 1381,271 & \\
Gumbel & $\begin{array}{l}\mathrm{Cs}< \\
\mathrm{Ck}<\end{array}$ & $\begin{array}{l}\mathrm{Cs}=-3,307 \\
\mathrm{Ck}=\end{array}$ & $\begin{array}{c}\text { Tidak } \\
\text { Memenuhi }\end{array}$ \\
& 5,4002 & 1381,271 & \\
\hline $\begin{array}{c}\text { Log } \\
\text { Pearson }\end{array}$ & $\mathrm{Cs} \neq 0$ & $\mathrm{Cs}=0,560$ & Memenuhi \\
\hline & $\begin{array}{l}\mathrm{Cs} \approx \\
3 \mathrm{Cv}+\end{array}$ & & $\begin{array}{c}\text { Tidak } \\
\text { Memenuhi }\end{array}$ \\
Normal & $\begin{array}{l}\mathrm{Cv}= \\
0,3\end{array}$ & $\mathrm{Cs}=0,016$ & \\
\hline
\end{tabular}

Sumber : Olah data

\subsection{Uji Sebaran Metode Chi Kuadrat}

Perhitungan :

$\mathrm{K}=1+3,322 \log \mathrm{n}=1+3,322 \log 5=$ $3,322 \approx 4$

DK $=\mathrm{K}-(\mathrm{R}+1)=4-(1+1)=2$ 
Tabel 6. Nilai Kritis untuk Uji Chi Kuadrat

\begin{tabular}{|c|c|c|c|c|c|c|c|c|}
\hline \multirow{2}{*}{ DK } & \multicolumn{7}{|c|}{$a$} \\
\cline { 2 - 9 } & 0,995 & 0,99 & 0,975 & 0,95 & 0,05 & 0,025 & 0,01 & 0,005 \\
\hline 1 & 0,0000393 & 0,000157 & 0,000928 & 0,00393 & 3,841 & 5,024 & 6,635 & 7,879 \\
\hline 2 & 0,100 & 0,021 & 0,058 & 0,103 & 5,991 & 7,378 & 9,210 & 10,579 \\
\hline 3 & 0,072 & 0,115 & 0,216 & 0,352 & 7,815 & 9,348 & 11,345 & 12,838 \\
\hline 4 & 0,207 & 0,297 & 0,485 & 0,711 & 9,488 & 11,143 & 13,277 & 14,860 \\
\hline 5 & 0,412 & 0,554 & 0,831 & 1,145 & 11,070 & 12,832 & 15,086 & 16,750 \\
\hline 6 & 0,676 & 0,872 & 1,237 & 1,635 & 12,592 & 14,449 & 16,812 & 18,548 \\
\hline 7 & 0,989 & 1,239 & 1,690 & 2,167 & 14,067 & 16,013 & 18,475 & 20,278 \\
\hline 8 & 1,344 & 1,646 & 2,180 & 2,733 & 15,507 & 17,535 & 20,090 & 21,955 \\
\hline 9 & 1,735 & 2,088 & 2,700 & 3,325 & 16,919 & 19,023 & 21,666 & 23,589 \\
\hline 10 & 2,156 & 0,558 & 3,247 & 3,940 & 18,307 & 20,483 & 23,209 & 25,188 \\
\hline
\end{tabular}

Sumber : Olah data

Untuk DK $=2$, signifikan $(\mathrm{a})=5 \%$ maka dari

Tabel 6, harga $\mathrm{X}^{2} \mathrm{Cr}=5,991$.

$$
\begin{aligned}
& E f=\frac{\sum n}{\sum K}=\frac{5}{4}=1,25 \\
& \Delta x=\frac{K_{\text {terbesar }}-K_{\text {terkecil }}}{K-1}=\frac{1,254-0,644}{4-1} \\
& =0,133 \\
& \frac{1}{2} \Delta x=0,067 \\
& X_{\text {awal }}=\left[R_{\text {terkecil }}-\frac{1}{2} \Delta x\right] \\
& =(0,644-0,101)=0,783
\end{aligned}
$$

Tabel 7. Hitungan $\mathrm{X}^{2} \mathrm{Cr}$

\begin{tabular}{|c|c|c|c|c|}
\hline $\begin{array}{c}\text { Nilai Batas Tiap } \\
\text { Kelas }\end{array}$ & Ef & Of & $\begin{array}{c}(\text { Ef - Of } \\
)^{2}\end{array}$ & $\begin{array}{c}(\text { Ef - Of })^{2} / \\
\text { Ef }\end{array}$ \\
\hline $\begin{array}{c}0,783<\mathrm{Ri}< \\
0,850\end{array}$ & 1,25 & 2 & 0,5625 & 0,450 \\
\hline $\begin{array}{c}0,850<\mathrm{Ri}< \\
0.917\end{array}$ & 1,25 & 1 & 0,0625 & 0,050 \\
\hline $\begin{array}{c}0.917<\mathrm{Ri}< \\
0.983\end{array}$ & 1,25 & 1 & 0,0625 & 0,050 \\
\hline $\begin{array}{c}0,983<\mathrm{Ri}< \\
1.050\end{array}$ & 1,25 & 1 & 0,0625 & 0,050 \\
\hline Jumlah & 5 & 5 & & 0,600 \\
\hline
\end{tabular}

Sumber : Olah data

Karena nilai $\mathrm{X}^{2} \mathrm{Cr}$ analisis $<\mathrm{X}^{2} \mathrm{Cr}(0.600<$ 5,991 ) maka untuk menghitung curah hujan rencana dapat menggunakan distribusi $\log$ Pearson Type III.

\subsection{Distribusi Curah Hujan Rencana}

Analisis curah hujan rencana ini bertujuan untuk mengetahui besarnya curah hujan maksimum dalam periode ulang tertentu yang nantinya dipergunakan untuk perhitungan debit banjir rencana.

Dalam perencanaan dam pengendali sedimen Kali Pacal, curah hujan rencana yang dipakai adalah curah hujan rencana dengan periode ulang 5 tahun Oleh karena itu dicari curah hujan rencana untuk periode 5 tahun, berdasarkan curah hujan rata - rata daerah aliran yang sudah diketahui.

\section{Distribusi Log Pearson Type III}

Perhitungan curah hujan rencana dengan metode Log Pearson III menggunakan parameter - parameter statistik Parameter yang digunakan adalah sebagai berikut :

Nilai Rata-Rata $(\log X) \quad=2,651$

Deviasi Standart $(\mathrm{Sx})=0,043$

Koefisien Skewness (Cs ) $\quad=0,560$

Harga $\mathrm{K}$ tergantung nilai Cs yang sudah didapat, seperti terdapat pada Tabel 2.4, untuk Cs = 0,734 dengan periode ulang 5 tahun, nilai $\mathrm{k}=$ 0,856 .

$\log R=2,651+(0,856 * 0,043)=2,687$

$\mathrm{R} \quad=486.587 \mathrm{~mm}$

\section{Perhitungan Debit Banjir Rencana}

Untuk menghitung debit banjir rencana digunakan hasil perhitungan intensitas curah hujan periode ulang 5 tahun. Besarnya debit rencana dapat ditentukan berdasarkan besarnya curah hujan rencana dan karakteristik daerah aliran sungai. Adapun data yang diperlukan adalah :

Luas DPS Kali Pacal $(\mathrm{A}) \quad=12,97 \mathrm{Km}^{2}$

Panjang Sungai $(\mathrm{L}) \quad=66 \mathrm{Km}$

Kemiringan Sungai $(\mathrm{i})=0.0393$

\section{Metode Harpes}

Metode Harpes digunakan pada luas DPS $<300 \mathrm{Km}$

Rumus :

$$
\begin{aligned}
& Q=\alpha \times \beta \times q \times A \\
& t=0,1 \times L^{0,8} \times i^{-0,30} \\
& a=\frac{1+\left(0,012 \times A^{0,70}\right)}{1+\left(0,075 \times A^{0,07}\right)} \\
& \frac{1}{\beta}=1+\frac{t+\left(3,70 \times 10^{0,40 t}\right)}{t^{2}+15} x \frac{A^{0,75}}{12}
\end{aligned}
$$

Dimana :

$\mathrm{Q}$ = Debit banjir rencana pada periode tertentu $\left(\mathrm{m}^{3} /\right.$ det $)$

$\mathrm{A}=$ koefisien limpasan air hujan

$\beta=$ Koefisien pengurangan Luas Daerah 
hujan.

$\mathrm{Q}$ = Intensitas maksimum jatuhnya hujan rata-rata $\left(\mathrm{m}^{3} / \mathrm{det} / \mathrm{km}\right)$

A = Luas Daerah Pengaliran sungai $\left(\mathrm{Km}^{2}\right)$

$\mathrm{t} \quad=$ waktu konsentrasi hujan (jam)

$\mathrm{L}=$ Panjang sungai $(\mathrm{km})$

$\mathrm{I}=$ Kemiringan Sungai

Perhitungan :

$$
\begin{gathered}
t=0,1 \times L^{0,8} \times i^{-0,30} \\
t=0,1 \times 66^{0,8} \times 0,0393^{-0,30}=7,539 \mathrm{jam} \\
a=\frac{1+\left(0,012 \times A^{0,70}\right)}{1+\left(0,075 \times A^{0,07}\right)} \\
a=\frac{1+\left(0,012 \times 12,97^{0,70}\right)}{1+\left(0,075 \times 12,97^{0,07}\right)}=0,739 \\
\frac{1}{\beta}=1+\frac{t+\left(3,70 \times 10^{0,40 t}\right)}{t^{2}+15} \times \frac{A^{0,75}}{12} \\
\frac{1}{\beta}=1+\frac{7,539+\left(3,70 \times 10^{0,40 t}\right)}{7,539^{2}+15} \times \frac{12,97^{0,75}}{12} \\
=5,849 \\
\beta=2,925
\end{gathered}
$$

Untuk $\mathrm{t}<2$ jam digunakan rumus :

$r=\frac{t * r}{t+1-0,0008(260-R)(2-t)^{2}}$

Untuk $\mathrm{t}>2$ jam digunakan rumus :

$$
\begin{aligned}
& r=\frac{t * R}{t-1} \\
& q=\frac{r}{3,6 * t}
\end{aligned}
$$

Dimana :

$\mathrm{R}=$ curah hujan periode ulang tertentu $(\mathrm{mm})$ Dari perhitungan $\mathrm{t}$ diatas di dapat nilai : $\mathrm{t}=2,466>2$ jam maka :

$$
\begin{aligned}
r & =\frac{7,539 * 486,587}{7,539+1}=429,603 \\
q & =\frac{429,603}{3,6 * 7,539}=15,829 \\
& Q=\alpha \times \beta \times q \times \\
& =0,739 \times 2,925 \times 15,829 x \\
& =443,678 \mathrm{~m}^{3} / \mathrm{det}
\end{aligned}
$$

\section{Metode Rasional}

Metode ini digunakan anggapan bahwa DPS memiliki :
a. Intensitas curah hujan merata diseluruh DPS dengan
durasi

b. Lamanya curah hujan = waktu konsentrasi dari DPS

c. Puncak banjir dan intensitas curah hujan mempunyai tahun berulang yang sama

d. Luas DAS $<300 \mathrm{Km}^{2}$

Rumus :

$$
Q=\frac{C \times I \times A}{3,60}
$$

Dimana :

$\mathrm{C}=$ Koefisien Limpasan air hujan

I = intensitas curah hujan selama waktu

konsentrasi ( $\mathrm{mm} / \mathrm{jam})$

A $=$ Luas Daerah Pengaliran $\left(\mathrm{km}^{2}\right)$

$\mathrm{Q}=$ Debit maksimum $\left(\mathrm{m}^{3} /\right.$ det $)$

Intensitas dihitung menggunakan rumus Mononobe :

Dimana :

$$
I=\frac{R_{24}}{24} x\left(\frac{24}{t c}\right)^{2 / 3}
$$

$\mathrm{R} \quad=$ hujan maksimum (mm)

tc = waktu konsentrasi $(\mathrm{mm} / \mathrm{jam})$

waktu konsentrasi dihitung menggunakan rumus yang dikembangkan oleh Kirpich(1940), yang dapat ditulis sebagai berikut :

$$
\text { tc }=0,0133 L x i^{-0,6}
$$

Dimana :

$$
\begin{array}{ll}
\mathrm{tc} & =\text { waktu konsentrasi }(\mathrm{mm} / \mathrm{jam}) \\
\mathrm{L} & =\text { Panjang sungai }(\mathrm{km}) \\
\mathrm{S} & \text { = kemiringan sungai }
\end{array}
$$

Data :

$$
\begin{aligned}
& \mathrm{A} \quad=12,97 \mathrm{Km}^{2} \\
& \mathrm{~L} \quad=66 \mathrm{Km}=66.000 \mathrm{~m} \\
& \mathrm{R} 100=486,587 \mathrm{~mm} \\
& \mathrm{~S} \quad=0,0393 \\
& t c=0,0133 \mathrm{~L} \times \mathrm{i}^{-0,6} \\
& =0,0133 \times 66 \times 0,0393^{-0,6} \\
& =6,120 \text { jam }
\end{aligned}
$$

Intensitas hujan dapat dihitung setelah tc didapat :

$$
\begin{aligned}
& I=\frac{R_{24}}{24} x\left(\frac{24}{t c}\right)^{2 / 3} \\
& I=\frac{486,587}{24} x\left(\frac{24}{6,120}\right)^{2 / 3} \\
& I=50,417 \mathrm{~mm}
\end{aligned}
$$

\subsection{Koefisien Limpasan ( C ) :}

Angka koefisien limpasan merupakan indikator apakah suatu DAS telah mengalami gangguan. Besar kecilnya nilai $\mathrm{C}$ tergantung 
pada permebilitas dan kemampuan tanah dalam menapung air. Nilai $\mathrm{C}$ yang besar menunjukkan bahwa banyak air hujan yang menjadi limpasan. Koefisien lipasan permukaan pada kajian ini dihitung berdasarkan pola penggunaan lahan hasil inventarisasi dari Sub Balai Rehabilitasi Lahan dan Konversasi Tanah pada tahun 2014. Karena tata guna lahan di DPS Kali Pacal termasuk campuran, maka nilai tetapan $\mathrm{C}$ diberikan bobot (weighted) untuk memperoleh nilai rata-rata tertimbang. Perhitungan selengkapnya disajikan dalam Tabel 8.

Tabel 8. perhitungan Koefisien Limpasan (c) di DPS Kali Pacal

\begin{tabular}{|c|l|c|c|c|c|}
\hline $\begin{array}{c}\mathbf{N} \\
\mathbf{0}\end{array}$ & $\begin{array}{l}\text { Penggunaa } \\
\mathbf{n}\end{array}$ & $\begin{array}{c}\text { Luas } \\
\mathbf{( k m}^{2} \\
\mathbf{~ L a h a n ~}\end{array}$ & \%luas & $\mathbf{C}$ & $\begin{array}{c}\text { Cx\%lua } \\
\mathbf{s}\end{array}$ \\
\hline \multirow{2}{*}{1} & $\begin{array}{l}\text { Hutan } \\
\text { Alam }\end{array}$ & 1,25 & 9,638 & 5 & 2.409 \\
& Hutan & & & & \\
2 & Industri & 0,65 & 5,012 & 0.3 & 1.503 \\
& & & & 0.2 & \\
3 & Pemukiman & 4,62 & 35,620 & 5 & 8.905 \\
4 & Sawah & 6,45 & 49,730 & 0.2 & 9.946 \\
\hline & & 12,9 & 100.00 & & 22.764 \\
& & 7 & 0 & & \\
\hline
\end{tabular}

Sumber : Olah data

Perhitungan debit banjir dengan Metode Rasional

$Q=\frac{C \times I \times A}{3,60}$

$Q=\frac{2,276 \times 50,417 \times 12,97}{3,60}$

$Q=413,495 \mathrm{~m}^{3} /$ det

Metode Melchior digunakan untuk DAS > 100 $\mathrm{Km}$

Rumus :

$Q=\alpha \times \beta \times q \times A$

$\beta=\frac{108+750 A}{150+A}$

$T=\frac{1000 L}{3600 v}$

$v=1,31 \sqrt[5]{\beta \cdot q \cdot A \cdot i^{2}}$

$n F=1 / 4 \pi a b=1 / 4 \times 3,14 \times 20 \times 66=1036,2$

$\mathrm{km}^{2}$

$\alpha=0,52$

Dimana :

$\mathrm{Q}=$ Debit banjir rencana pada periode tertentu $\left(\mathrm{m}^{3} /\right.$ det $)$
A = koefisien limpasan air hujan

$\beta=$ Koefisien pengurangan Luas Daerah hujan.

$\mathrm{q}=$ intensitas maksimum jatuhnya hujan rata-rata $\left(\mathrm{m}^{3} / \mathrm{det} / \mathrm{km}\right)$

A $\quad=$ Luas Daerah Pengaliran sungai $\left(\mathrm{Km}^{2}\right)$

= waktu konsentrasi hujan (jam)

$\mathrm{L} \quad=$ Panjang sungai $(\mathrm{km})$

I $\quad=$ Kemiringan Sungai

Perhitungan:

$\beta=\frac{108+750 A}{150+A}$

$\beta=\frac{108+750 \times 12,97}{150+12,97}=14,235$

$\mathrm{nF}=1036,2 \mathrm{Km}^{2}$

$\mathrm{q}=4,3 \mathrm{~m}^{3} / \mathrm{km}^{2} / \mathrm{det}$

$v=1,31 \sqrt[5]{\beta \cdot q \cdot A \cdot i^{2}}$

$v=1,31 \sqrt[5]{0,52 \cdot 4,3 \cdot 12,97 \cdot 0,0393^{2}}$

$=0,704 \mathrm{~m} /$ det

$T=\frac{1000 L}{3600 v}$

$T=\frac{1000 \times 66}{3600.0,704}=12,904 \mathrm{jam}$

$R t=0,41 R 24$

$q=\frac{0,41 \times 2000}{3,6 \times 12,904}=4,294$

$=4,3 \mathrm{~m}^{3} / \mathrm{km}^{2} /$ det cocok dengan yang diatas.

$Q=0,52 \times 14,235 \times 4,3 \times 12,97 \times \frac{486,587}{486,587}$

$=412,823 \mathrm{~m}^{3} / \mathrm{detik}$

Dari hasil perhitungan metode-metode sebelumnya, maka dapat dibuat kesimpulan seperti pada Tabel 9.

Tabel 9. Debit banjir yang dipakai

\begin{tabular}{|c|c|}
\hline metode & $\begin{array}{c}\text { Debit Banjir 5 Tahun } \\
\left(\mathrm{m}^{3} / \text { detik }\right.\end{array}$ \\
\hline Harpes & 443,678 \\
\hline Rasional & 413,495 \\
\hline Melchoir & 412,824 \\
\hline
\end{tabular}

Sumber : Olah data

Debit Banjir yang digunakan adalah tertinggi yaitu dari perhitungan Metode Harpes yaitu Q5 = 443,678 $\mathrm{m}^{3} / \mathrm{det}$. Untuk perencanaan dam pengendali sedimen Kali Pacal digunakan Qdesign $=444 \mathrm{~m}^{3} /$ det . 


\section{KESIMPULAN}

\subsection{Kesimpulan}

Dari hasil penelitian tersebut diperoleh bahwa perhitungan dengan metode Harpes diketahui bahwa debit banjir 5 Tahun adalah 443,678 $\mathrm{m}^{3} /$ detik, metode Rasional menghasilkan 413,495 $\mathrm{m}^{3} /$ detik dan metode Melchoir menghasilkan 412,824 m³/detik.

\subsection{Saran}

Dilihat dari keadaan diatas perencana mempunyai saran - saran sebagai berikut :

1. Pengelolaan check dam hendaknya dilakukan secara terintegrasi.

2. Hendaknya dilakukan perencanaan check dam secara menyeluruh.

\section{DAFTAR PUSTAKA}

[1] si. M. Mac Donald Partners, Buku Panduan Pelaksanaan $O \&$ P Pengairan"Proyek Irigasi Jawa Timur : Dirjen Pengairan Dep. PU Tahun.1984

[2] Erman Mawardi. Desain Hidraulik Bangunan Irigasi Alfabeta: Dipl. AIT Bandung.2007

[3] Imam Subarkah "Hidrologi, untuk Perencanaan Bangunan Air", Idea Dharma Bandung 1980.

[4] Mansoer. Syamsudin. Perencanaan Teknis Rehabilitasi Jaringan Irigasi (Saluran dan Bangunan).: Dipl. HE Pelatihan PISP Bandung April. 2008

[5] Roestam Sjarief, Ph. D, Edisi II "Pengelolaan Sumber Daya Air Terpadu“ ANDI Yogyakarta , ISBN : 978- 979 -29-0239-6 